\title{
Preparation and Loading with Rifampicin of Sub-50 nm Poly(ethyl cyanoacrylate) Nanoparticles by Semicontinuous Heterophase Polymerization
}

\author{
H. Saade, ${ }^{1}$ C. Barrera, ${ }^{1}$ R. Guerrero, ${ }^{2}$ E. Mendizábal, ${ }^{3}$ J. E. Puig, ${ }^{4}$ and R. G. López ${ }^{1}$ \\ ${ }^{1}$ Departamento de Procesos de Polimerización, Centro de Investigación en Química Aplicada, Boulevard Enrique Reyna No. 140, \\ 25294 Saltillo, COAH, Mexico \\ ${ }^{2}$ Síntesis de Polímeros, Centro de Investigación en Química Aplicada, Boulevard Enrique Reyna No. 140, \\ 25294 Saltillo, COAH, Mexico \\ ${ }^{3}$ Departamento de Química, Universidad de Guadalajara, Boulevard M. García-Barragán No. 1451, 44430 Guadalajara, JAL, Mexico \\ ${ }^{4}$ Ingeniería Química, Universidad de Guadalajara, Boulevard M. García-Barragán No. 1451, 44430 Guadalajara, JAL, Mexico
}

Correspondence should be addressed to R. G. López; guillermo.lopez@ciqa.edu.mx

Received 2 May 2016; Revised 23 June 2016; Accepted 28 June 2016

Academic Editor: Md Nurunnabi

Copyright @ 2016 H. Saade et al. This is an open access article distributed under the Creative Commons Attribution License, which permits unrestricted use, distribution, and reproduction in any medium, provided the original work is properly cited.

\begin{abstract}
We report the preparation of poly(ethyl cyanoacrylate) (PECA) nanoparticles by semicontinuous heterophase polymerization carried out at monomer starved conditions at three monomer addition rates. Particles in the nanometer range were obtained, the size of which diminishes with decreasing monomer addition rate as shown by the fact that particles with mean diameters of ca. 42 and $30 \mathrm{~nm}$ were obtained at the faster and intermediate dosing rates, respectively, whereas two populations of particles, one of 15.5 and the other of $36 \mathrm{~nm}$ in mean diameters, were produced at the slower dosing rate. The obtained molecular weights were from 2,200 to 3,500 g/mol, depending on the addition rate, which are typical of the anionic polymerizations of cyanoacrylates in aqueous dispersions at low pHs. The rifampicin (RIF) loading into the nanoparticles was successful since the entire drug added was incorporated. The drug release study carried out at $\mathrm{pH}$ of 7.2 indicated a faster release from the free RIF at intermediate and larger release times as expected since, in the nanoparticles, first the drug has to diffuse through the nanoparticle structure. The comparison of several drug release models indicates that the RIF release from PECA nanoparticles follows that of Higuchi.
\end{abstract}

\section{Introduction}

Poly(alkyl cyanoacrylates), PACA, are a family of biodegradable polymers that are being intensively investigated for the development of drug delivery nanoparticles [1-3]. These polymeric nanostructures are usually obtained by anionic emulsion polymerization [2]. Couvreur et al. first reported the emulsion polymerization of the alkyl cyanoacrylates, in particular of methyl cyanoacrylate and ethyl cyanoacrylate (ECA), obtaining latexes that contained nanoparticles with mean diameter of $200 \mathrm{~nm}$ and less than $1 \%$ in solid content [4]. These authors also reported the nanoparticles loading with fluorescein and daunorubicin, being the first to propose PACA nanoparticles as drug carriers. In the following years the research on PACA nanoparticles was significant [5-14], rendering fundamental knowledge about the conditions and mechanisms involved in their preparation. In parallel, a number of reports on drug-loaded PACA nanoparticles also appeared [3, 15-19].

The reports on PACA nanoparticles preparation have allowed knowing that the type and concentration of surfactant [5-10] and the initial $\mathrm{pH}[5,9,11-14]$ mainly determine the particle size. Different types of Dextrans [5, 9, 1113] and Tweens (TW) $[4,5,10,11]$ are the most tested surfactants, the latter being the ones that enable obtaining the smaller PACA nanoparticle sizes. On this particular issue, it could be appointed that Behan et al. [12] obtained poly(butyl cyanoacrylate) (PBCA) nanoparticles with mean diameter around $400 \mathrm{~nm}$ using Dextran 70 at $\mathrm{pHs}$ between 2 and 3. On the other hand, Douglas et al. [5] prepared 
PBCA nanoparticles with average particle diameter close to $50 \mathrm{~nm}$ by polymerizing in emulsions stabilized with Tween 60 (TW60) at $\mathrm{pH}$ of 2.25. Larger particles were obtained when Tweens (TW20 and TW40) with lower molecular weights were employed, which suggests an inverse relationship between particle size and Tween molecular weight. The work of Yang et al. [8] is remarkable because of the very small PBCA particles reported. The authors show micrographs where particles with diameters smaller than $50 \mathrm{~nm}$ are identified; however, they mention that there is another population composed of much larger particles (not shown in the micrographs). Unfortunately the authors do not include particle size histograms to know more precisely the sizes of the obtained particles. Incidentally, the absence of particle size distributions from electron microscopy measurements in the quoted works is noticeable [4-14], being the mean particle sizes reported, those obtained by quasi-elastic light scattering (QLS).

Recently our group documented the synthesis of poly(ethyl cyanoacrylate), PECA, nanoparticles by a technique named as semicontinuous heterophase polymerization at monomer-starved conditions [20]. Here we demonstrated that modulating the monomerdosing rate it is possible to obtain latexes containing only one population of very small particles. In fact, a latex composed of PECA particles with $42.3 \mathrm{~nm}$ in mean diameter, determined by electron microscopy, and a solid content close to $10 \%$, was obtained. Such small particle size together with relatively high solid content is not common in the synthesis of PACA nanoparticles. In fact, mean particle diameters over $100 \mathrm{~nm}$ are usual in reports on drug-loaded PACA nanoparticles [2, 3, 15-19]. Nevertheless, nanoparticles ranging from 10 to $50 \mathrm{~nm}$ in diameter are very attractive as drug delivery carriers because of the expected increase in their efficacy $[21,22]$. Their smallness would increase the ability to cross through intestinal walls entering the blood stream [21] and reducing their clearance by the immunological system [23].

In continuation of our previous work, herein we report the preparation of PECA nanoparticles with mean diameter smaller than $40 \mathrm{~nm}$ achieved by modulating the dosing rate of monomer. Furthermore, the same surfactant previously used, Tween 80 (TW80), as well as the $\mathrm{pH}$ at which the smaller particle size was obtained, 1.75, was used in the present work. Loading of PECA nanoparticles with rifampicin (RIF) and the corresponding release study were also included. RIF, a first-line antituberculosis drug, was chosen because of the great interest in the development of more efficacy ways for drug administration as well as to reduce the dose frequency [24].

\section{Materials and Methods}

2.1. Materials. ECA (99\%), dichloromethane (99.5\%), and spectrophotometric grade chloroform were purchased from Sigma-Aldrich (México); HPLC-grade tetrahydrofuran (THF) was provided from Merck; TW80 was obtained from Oxiteno (Guadalajara, México); RIF was obtained from Lupin Tarapur (India). All chemicals were used as received.
Deionized and triple-distilled water was drawn from a T S Barnstead E-Pure 4-Holder Water Purification System.

2.2. Polymerizations. Reactions were conducted in a $25 \mathrm{~mL}$ jacketed glass reactor equipped with a reflux condenser and mechanical agitation following the procedure described below. $20 \mathrm{~g}$ of water adjusted to $\mathrm{pH}$ of 1.75 using a mixture of phosphates and $0.35 \mathrm{~g}$ of TW80 were charged into the reactor, after which the mixture was subjected to $450 \mathrm{rpm}$ agitation and the temperature stabilized at $35^{\circ} \mathrm{C}$; the reaction started with the beginning of the monomer addition. In all polymerizations, $2 \mathrm{~g}$ of ECA was added at different dosing rates $\left(F_{o}\right)(0.0055,0.011$, and $0.017 \mathrm{~g} / \mathrm{min})$ with a dosing pump (Kd Scientific-100). The polymerizations were stopped at the end of the dosing period by turning off the water recirculation system used for maintaining the reaction temperature and then transferring the latex to a vessel previously cooled in an ice-water bath. Due to the relatively large sample amounts required for the characterizations, a series of runs were carried out for each polymerization. For a given $F_{o}$, the addition period in the polymerization was divided into 5 intervals; then a run for each interval was carried out, stopping the polymerization and collecting all the latex at the end of each of them to determine conversion by gravimetry and molecular weight. Particle size was only measured in the final latex. For the dosing rate of $0.005 \mathrm{~g} / \mathrm{min}$, the intervals 1 , $2,3,4$, and 5 correspond to values of the normalized dosing time, $t_{r}$, equal to $0.20,0.40,0.62,0.83$, and 1 , respectively; here the normalized time is the ratio of the sampling time $t$ divided by the total addition time. For the dosing rate of $0.017 \mathrm{~g} / \mathrm{min}$, the $t_{r}$ values for the same intervals were $0.21,0.42,0.63,0.83$, and 1. With this protocol, the amount of latex obtained was enough to make all the required characterizations. Samples during the polymerization at $0.011 \mathrm{~g} / \mathrm{min}$ were not taken; only the final latex was analyzed.

\subsection{Characterization}

2.3.1. Particle Size. Determination of the particle size distributions for latexes samples was carried out in a JEOL JSM$7401 \mathrm{~F}$ field emission scanning electron microscope (FE-SEM) operated at scanning-transmission mode (STEM) using a transmission electron detector SM74230RTD. For the measurements, a dilution containing about $2.5 \mathrm{~g}$ of solids per liter was prepared, depositing one drop of it on a copper grid, and allowed to dry. After that the samples were stained with a drop of a 2 wt.\% aqueous solution of phosphotungstic acid. The diameters of a variable number of particles were manually measured one by one from the set of micrographs with the image analysis program Image $1.37 \mathrm{c}$. From these data, particle size histograms were elaborated and $D_{w}, D_{n}$, and PDI $\left(=D_{w} / D_{n}\right), D_{w}$ and $D_{n}$ being the weight- and numberaverage diameters, respectively, and PDI, the polydispersity index, were calculated using the following equations:

$$
\begin{aligned}
D_{n} & =\frac{\sum_{i} n_{i} D_{i}}{\sum_{i} D_{i}}=\frac{\sum n_{i} D_{i}}{n}, \\
D_{w} & =\frac{\sum_{i} n_{i} D_{i}^{4}}{\sum_{i} n_{i} D_{i}^{3}} .
\end{aligned}
$$


2.3.2. Molecular Weight Determination. For measuring the molecular weight distribution (MWD) and the average molecular weights of the polymer, the latexes samples were lyophilized and dissolved in HPLC-grade THF, used as the mobile phase. An Agilent PL-GPC50 gel permeation chromatograph (GPC) equipped with three columns (Agilent PLgel) and a refractive index detector was employed. The GPC was calibrated with polystyrene (PS) standards (Polyscience) covering the molecular weight range of $6.0 \times 10^{2}$ to $3.0 \times 10^{6} \mathrm{~g} / \mathrm{mol}$. The reported average molecular weights were those provided by the equipment, so they are relative to polystyrene.

\subsection{Chemical Structure Analysis}

Nuclear Magnetic Resonance (NMR) Spectroscopy. The polymer samples were analyzed by ${ }^{1} \mathrm{H}$ (16 scans) and ${ }^{13} \mathrm{C}(12,000$ scans) NMR in a Bruker- $400 \mathrm{MHz}$ spectrometer. Acetone-d6 was used as solvent and the analyses were performed at room temperature.

Fourier Transform Infrared (FTIR) Spectroscopy. This analysis was carried out in a Spectrophotometer Thermo Nicolet/Magna-550. For this, a sample of the dried polymeric material was grinded with potassium bromide powder and subsequently pressed to form a disk, which was analyzed in the apparatus.

2.5. RIF Loading Process. The procedure to load the drug within the nanoparticles was as follows: $5.75 \mathrm{~g}$ of a latex from a polymerization carried out at $0.011 \mathrm{~g} / \mathrm{min}$ was diluted with $10.25 \mathrm{~g}$ of water and then charged again into the reactor where the polymerization was performed. After that, the addition of a $0.6 \mathrm{~g}$ of RIF-DCM solution with $15 \mathrm{wt} . \%$ drug was initiated, maintaining the dispersion at $25^{\circ} \mathrm{C}$ and $450 \mathrm{rpm}$ agitation. The addition was carried out by intermittent shots of the solution, allowing the dispersion to recover the original appearance before the next shot. The total addition time was $260 \mathrm{~min}$. The latex obtained from the loading process was filtered through a $0.2 \mu \mathrm{m}$ filter and a sample of the filtered latex was taken for RIF concentration determinations. The RIF concentration in the nanoparticles was determined with a Shimadzu multiespec-1501UV-vis spectrophotometer by analyzing the dried solid, resulting from the lyophilized sample, dissolved in spectrophotometric grade chloroform. For this purpose, a calibration curve was elaborated ranging from 10 to $100 \mathrm{ppm}$ of RIF by dissolving the required quantities of the drug in spectrophotometric grade chloroform and reading the absorbance at $348 \mathrm{~nm}$. The analysis of the sample required the dissolution of $2 \mathrm{mg}$ of loaded nanoparticles in $10 \mathrm{~mL}$ of spectrophotometric grade chloroform.

2.6. In Vitro RIF Release Studies. These studies were carried out using the dialysis technique. For this procedure, $26 \mathrm{mg}$ of RIF-loaded nanoparticles dispersed in $2 \mathrm{~mL}$ of phosphate buffer solution at $\mathrm{pH}$ of 7.2 was loaded into a dialysis membrane bag $(12,500 \mathrm{~g} / \mathrm{mol}$ in exclusion size), which was then sealed. After that, the prepared membrane

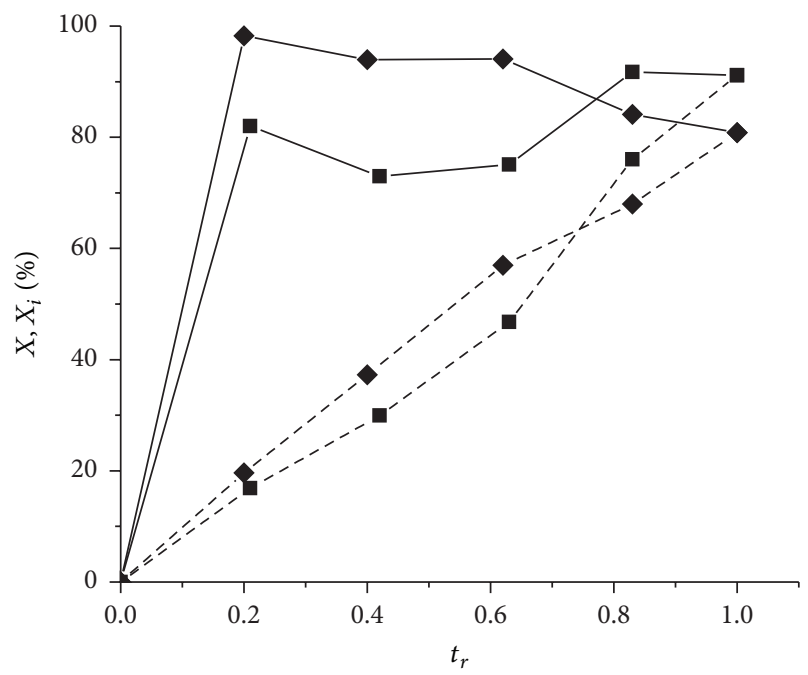

FIGURE 1: Evolution of instantaneous, $X_{i}(-)$ and global, $X\left(-\right.$ - $^{-}$ conversions with relative time for the polymerizations of ECA at two monomer dosing rates: $0.0055(\diamond)$ and $0.017(\bullet) \mathrm{g} / \mathrm{min}$.

was introduced into a $0.5 \mathrm{~L}$ phosphate buffer solution at $\mathrm{pH}$ of 7.2, applying intense magnetic agitation and maintaining the system temperature at $37^{\circ} \mathrm{C}$. One $\mathrm{mL}$ samples of the buffer solution were then taken at predetermined times during the test and analyzed from the intensity of the absorbance band at $334 \mathrm{~nm}$ in a Shimadzu multiespec-1501UV-vis spectrophotometer. After each sampling, $1 \mathrm{~mL}$ of the buffer was added to the buffer solution to maintain the original volume. For comparison, a sealed dialysis membrane bag containing $10 \mathrm{mg}$ of RIF dispersed in $2 \mathrm{~mL}$ of phosphate buffer solution at $\mathrm{pH}$ of 7.2 was also immersed into $0.5 \mathrm{~L}$ of the same buffer solution to determine the profile of the drug dissolution in the buffer under similar conditions to that used with the RIF-loaded nanoparticles and the same sampling sequence. The release tests were carried out in duplicate for RIF-loaded nanoparticles and in triplicate for free-RIF.

It is worth mentioning that RIF instability in human plasma ( $\mathrm{pH} 7.2$ to 7.4) is well known. However, it is also known that RIF maintains its antibacterial activity between $\mathrm{pH}$ values from 5.5 to 8 [25] as demonstrated by the number of years that this drug has been used systematically against tuberculosis. Literature is plenty of reports on RIF-nanostructures preparation, which includes drug release studies. In these studies RIF instability is not taken into account, as it does not affect the release profiles. Furthermore, the main method to determine RIF concentration in the releasing medium is UV spectrophotometry, because the selected signal to follow such concentration is not affected by the change in the chemical structure of drug [26-28].

\section{Results and Discussion}

3.1. Kinetics. Figure 1 shows the instantaneous conversion $\left(X_{i}\right)$ and the global conversion $(X)$ as a function of the normalized time $\left(t_{r}\right)$ for the runs made at the slowest $(0.0055 \mathrm{~g} / \mathrm{min})$ and fastest $(0.017 \mathrm{~g} / \mathrm{min})$ addition rates. The 


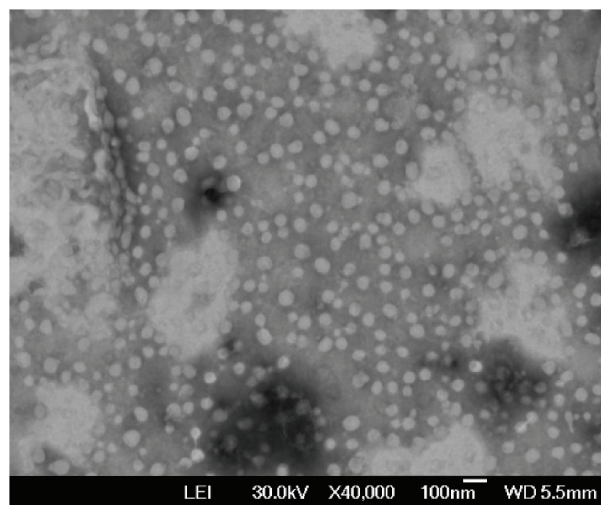

(a)

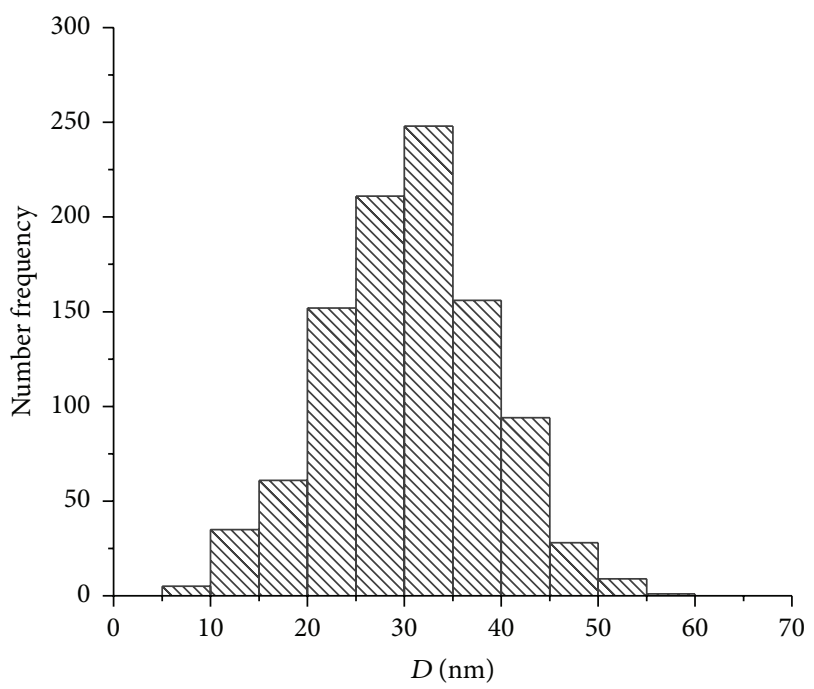

(b)

FIGURE 2: Representative STEM micrograph (a) and the corresponding particle size histogram (b) of a sample of PECA latex from the polymerization at a monomer dosing rate of $0.011 \mathrm{~g} / \mathrm{min}$.

instantaneous conversion is the fraction of added monomer up to time $t$ that has changed into polymer, the global conversion is defined as the fraction of total monomer converted to polymer at time $t$, and $t_{r}$ is the ratio of the sampling time $t$ divided by the total addition time, as indicated in the Experimental Section; this normalization allows comparing the curves in Figure 1 at the same overall fraction of added monomer inasmuch as the effective addition times differ substantially. This plot clearly reveals that $X_{i}$ increases rapidly with reaction time reaching values near $80 \%$ for the slowest addition rate and $100 \%$ for the slowest one when $t_{r} \approx$ 0.2 . High instantaneous conversions indicate that monomerstarved conditions were achieved for both monomer addition rates, while the difference between the $X_{i}$ curves up to $t_{r} \approx$ 0.6 suggests that there is an inverse relationship between monomer dosing rate and instantaneous conversion. At the end of the polymerization, however, the instantaneous conversion at the slowest dosing rate falls below the one attained for the fastest dosing rate, which as we will show and discuss below, is related to the agglomeration of the small particles to produce another population of larger particles. Our group reported the above mentioned inverse relationship for the free-radical semicontinuous heterophase polymerization (SHP) of several monomers [29-31] but to our knowledge, our previous paper [20] and this one are the first reports on anionic SHP of alkyl cyanoacrylates in aqueous dispersions stabilized with surfactants. As we have explained elsewhere [29-31], in monomer-starved conditions, the volumetric growth of the particles diminishes as the dosing rate is reduced, leading as a consequence to the formation of a larger number of particles of smaller size and faster depletion of fed monomer [32].

3.2. Particle Size. Table 1 depicts the final $D_{n}$ and PDI values obtained from the runs made at the different dosing
TABLE 1: Average particle size and particle size polydispersity from the latexes obtained at the end of the polymerizations of ECA carried out at different monomer dosing rates.

\begin{tabular}{lcccc}
\hline $\begin{array}{l}\text { Dosing rate } \\
(\mathrm{g} / \mathrm{min})\end{array}$ & \multicolumn{2}{c}{ Population 1 } & \multicolumn{2}{c}{ Population 2 } \\
\hline 0.0170 & $D_{n}(\mathrm{~nm})$ & PDI & $D_{n}(\mathrm{~nm})$ & PDI \\
$0.0110^{\mathrm{a}}$ & 42.3 & 1.4 & - & - \\
$0.0110^{\mathrm{b}}$ & 27.3 & 1.3 & - & - \\
0.0055 & 30.4 & 1.2 & - & - \\
\hline
\end{tabular}

Original run (a) and its replicate (b).

rates employed. Similarly to results obtained from other SHP reports [29-31], particle size decreases as the dosing rate diminishes from 0.0170 to $0.0055 \mathrm{~g} / \mathrm{min}$. Elsewhere we reported the data for the fastest dosing rate $(0.017 \mathrm{~g} / \mathrm{min})$, which revealed that only one particle population with $42.3 \mathrm{~nm}$ in $D_{n}$ was obtained [20]. Here the particle sizes we obtained from the two polymerizations at the dosing rate of $0.011 \mathrm{~g} / \mathrm{min}$ were similar since the measured mean diameters were 27.3 and $30.4 \mathrm{~nm}$ at final conversion for the original run and for the replica, respectively. However, and in contrast to the results at $0.017 \mathrm{~g} / \mathrm{min}$, the size distribution obtained at the slower dosing rate indicates a bimodal size population, with $D_{n}=15.5 \mathrm{~nm}$ for one population and $36.2 \mathrm{~nm}$ for the other one. Previously, we have suggested that the larger particles were produced by the aggregation of a fraction of the smaller ones in order to preserve the stability of the dispersion along the polymerization [20].

Figures 2 and 3 depict micrographs and the corresponding histograms of the polymerizations made at dosing rates of 0.011 and $0.0055 \mathrm{~g} / \mathrm{min}$, respectively. The micrograph shown in Figure 2 reveals the presence of spheroidal particles with certain degree of dispersion as indicated by the PDI of 1.3 and 


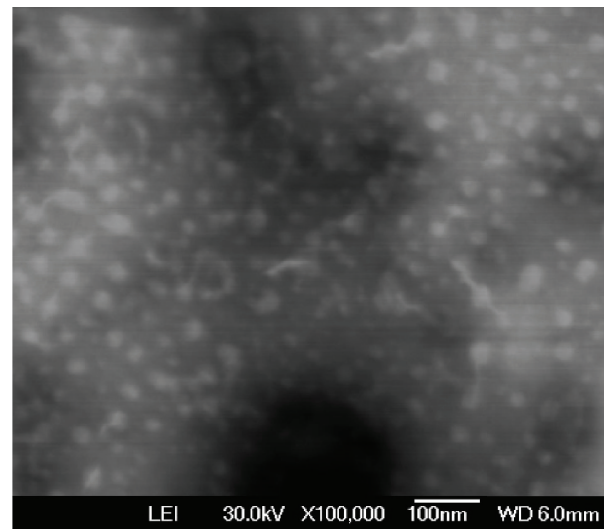

(a)

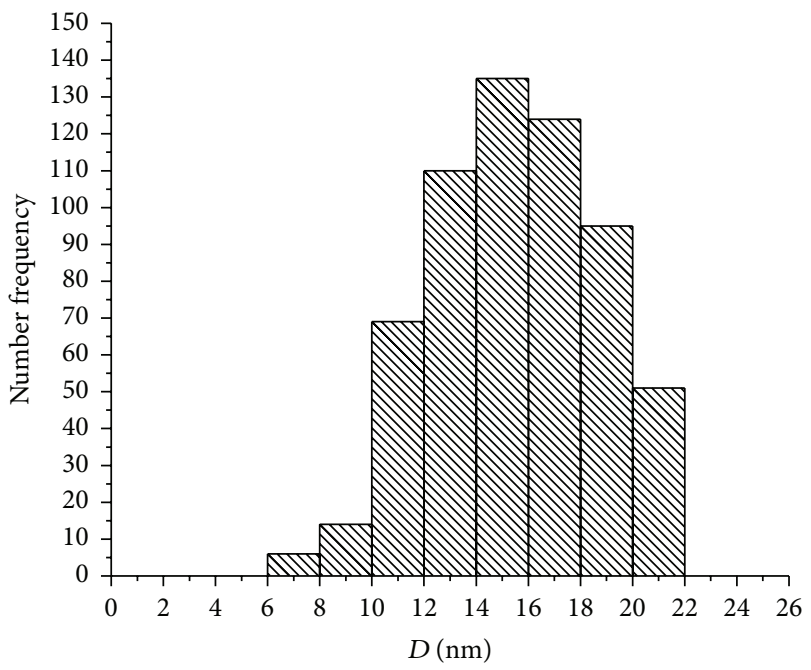

(b)

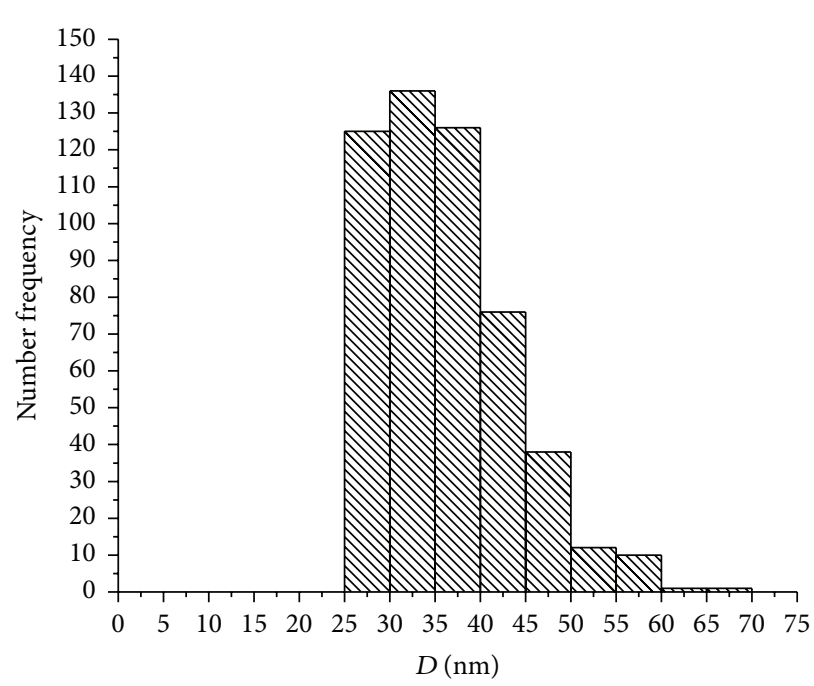

(c)

FIGURE 3: Representative STEM micrograph (a) of a sample of PECA latex from the polymerization at a monomer dosing rate of $0.0055 \mathrm{~g} / \mathrm{min}$. Histograms of the small (b) and large (c) particle populations identified are included.

1.2 for the two polymerizations (the original and its replicate) estimated from the data in the histograms. The micrograph in Figure 3 shows a more polydispersed particle distribution, where two populations can be observed and revealed by the histograms obtained from a set of micrographs. However, the low polydispersity of each one of the populations is noticeable.

Previously we have reported that, for the dosing rate of $0.017 \mathrm{~g} / \mathrm{min}$, the particle surface covered by one molecule of TW 80 was $1.6 \mathrm{~nm}^{2}$ and that a monomodal particle population of $42 \mathrm{~nm}$ in $D_{n}$ was produced; hence, we concluded that the surface coverage ratio was sufficiently small to stabilize the formed particles [20]. The procedure to estimate this surface coverage ratio consisted of first calculating the number concentration of particle $\left(N_{p}\right)$ in the latex with the following equation:

$$
N_{p}=\frac{6 C_{p}}{\pi \rho_{p} D_{n}^{3}}
$$

where $C_{p}$ is the polymer concentration in the latex $(\mathrm{g} / \mathrm{mL}$ of water) and $\rho_{p}$ the PECA density $(1.1 \mathrm{~g} / \mathrm{mL})[20]$. The number of surfactant molecules per $\mathrm{mL}$ of water $\left(N_{s}\right)$ was calculated from the molecular weight of the surfactant $(1,310 \mathrm{~g} / \mathrm{mol})$ and its weight used in the formulation employed for the polymerization. The values of $N_{p}$ and $N_{s}$ calculated in this way for the latex made at the dosing rate of $0.011 \mathrm{~g} / \mathrm{min}$ allowed estimating that 2.8 and $2.1 \mathrm{~nm}^{2}$ of particle surface, for the original run and its replicate, respectively, were covered by one surfactant molecule. Although these values are higher than that calculated for the dosing rate of $0.017 \mathrm{~g} / \mathrm{min}\left(1.6 \mathrm{~nm}^{2}\right)$, they are still small enough to stabilize the particles giving only one population. For the slowest dosing rate, two-particle size populations were produced, one with average number particle size of $15.5 \mathrm{~nm}$ and the other one with $36.2 \mathrm{~nm}$. The surface coverage area per molecule of TW80 was calculated from the average particle size of the smaller particle population giving a value of $3.6 \mathrm{~nm}^{2}$, which appears to be too large to produce a single population of particles. These results suggest that it is possible to reduce 


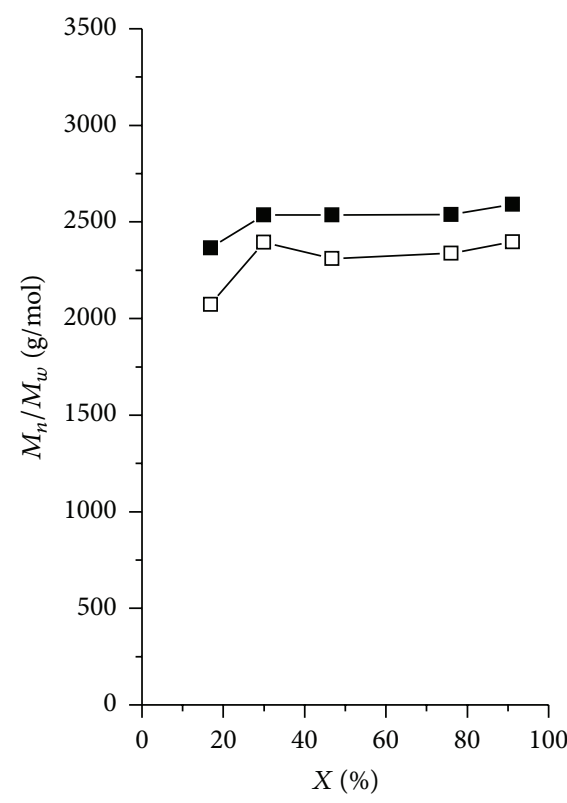

(a)

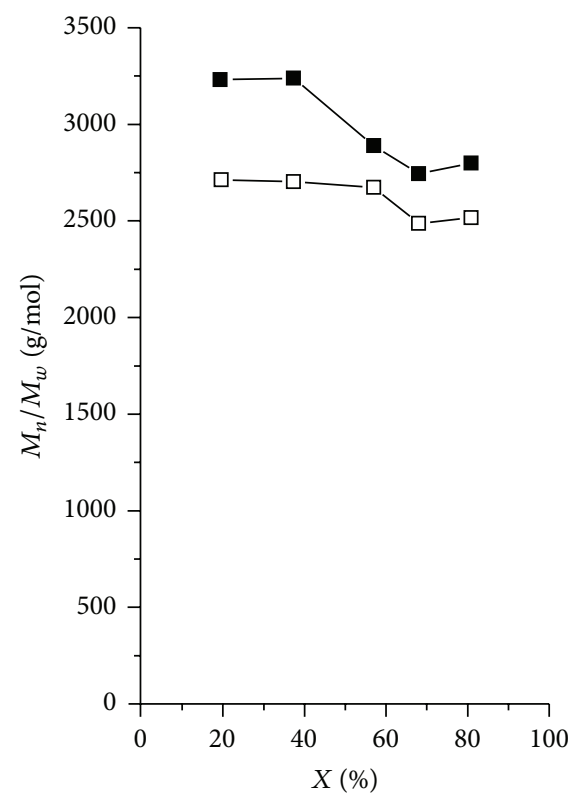

(b)

FIGURE 4: Evolution of average molecular weights $M_{w}(\boldsymbol{\square})$ and $M_{n}(\square)$ in the polymerizations of ECA at monomer dosing rates of 0.017 (a) and 0.0055 (b) g/min.

the particle size through a decrease in the monomer dosing rate; however, as the rate decreases the surface coverage area increases. Under the recipe and conditions used in this study, values as high as $2.8 \mathrm{~nm}^{2}$ per surfactant molecule still allow obtaining a single particle population. However, when this ratio increased to $3.6 \mathrm{~nm}^{2}$, two particle populations were formed. This indicates that between 2.8 and $3.6 \mathrm{~nm}^{2}$ there is a threshold limit value for the particle surface covered by one molecule of TW80, above which a fraction of the particle must aggregate to form another population and to increase the system stability.

From the direct relationship between particle size and monomer addition rate we can elucidate the kinetic behavior of the polymerizations. At the slowest addition rate, a larger number density of smaller particles is produced yielding a larger number of reaction sites and, as a consequence, faster reaction rates, which is evident at $0.2 \leq t_{r} \leq 0.6$. However, for $t_{r}>0.6, X_{i}$ diminishes due to the aggregation that produces another population of larger particles bringing as a result a reduction of the reaction sites. For the fastest addition rate, the increase of $X_{i}$ at $t_{r}>0.6$ could be related to the increment of the number density of particles, which should increase the number of reaction sites. Moreover, unlike the polymerization at slowest addition rate, there is no evidence here of particle aggregation. Literature reports of SHP of acrylic monomers have demonstrated that the formation of particles exists even at the final stages of polymerization [2931], which is in agreement with results presented here.

3.3. Molecular Weight. It has been reported that molecular weights of PACA synthesized in dispersed aqueous medium are quite small. El-Egakey et al. [33] studied the effect of surfactant concentration on the molecular weight of this kind of polymers and found weight-average molecular weights $\left(M_{w}\right)$ between 1,400 and 3,800 g/mol. Seijo et al. [6] polymerized isobutyl and isohexyl cyanoacrylates and obtained values of $M_{w}$ of ca. 2,500-3,000 g/mol. $M_{w}$ obtained here are also on the order of $2,500 \mathrm{~g} / \mathrm{mol}$ throughout the reaction for the addition rate of $0.017 \mathrm{~g} / \mathrm{min}$, with $M_{w} / M_{n}$ values, $M_{n}$ being the number-average molecular weight, of ca.1.1 (Figure 4(a)); for the slowest addition rate, $M_{w}$ is ca. $3,250 \mathrm{~g} / \mathrm{mol}$ up to conversions ca. $40 \%$ and then it drops to values around $2,750 \mathrm{~g} / \mathrm{mol}$ at larger conversions (Figure 4(b)). A similar behaviour is observed in the case of $M_{n}$ for the slowest addition rate. Furthermore, a low value (1.1) for $M_{w} / M_{n}$ is also noted.

In the emulsion polymerization of alkyl cyanoacrylates it is recognized that the growth of the polymeric chains ends when they enter in contact with a $\mathrm{H}^{+}$from the aqueous medium [12]. However, it is not clear whether the proton from the aqueous medium penetrates into the particle or the active extreme of the propagation chain and the proton meet near the surface of the growing particle. The larger molecular weights obtained at the slowest addition rate in the earlier stages of the reaction could have its origin in the large number density of small particles produced in this period; on the contrary, the low molecular weights at the fastest addition rate might be due to the smaller number density of particles. This should bring as a result a larger ratio of particles to protons in the aqueous medium at the slowest addition rate compared to the fastest addition one, which should result in a decrease in the frequency at which the protons interact with the active polymeric particles, yielding consequently a decrease in the frequency of termination and larger molecular weights. However, the aggregation of particles at the slowest 


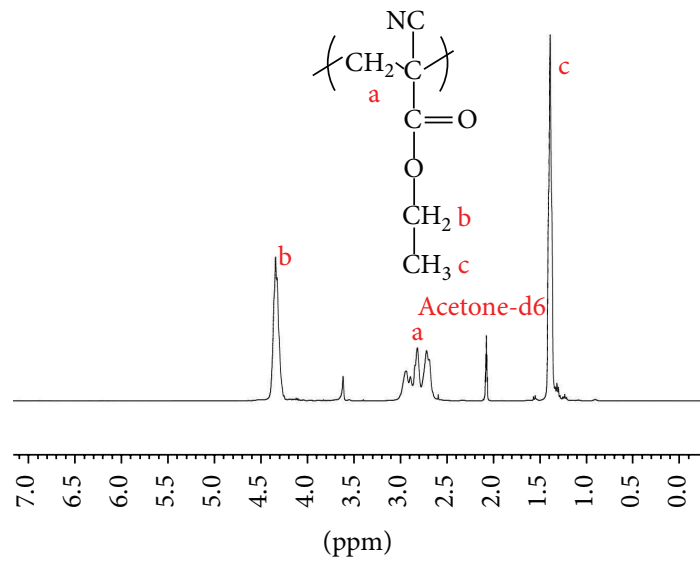

(a)

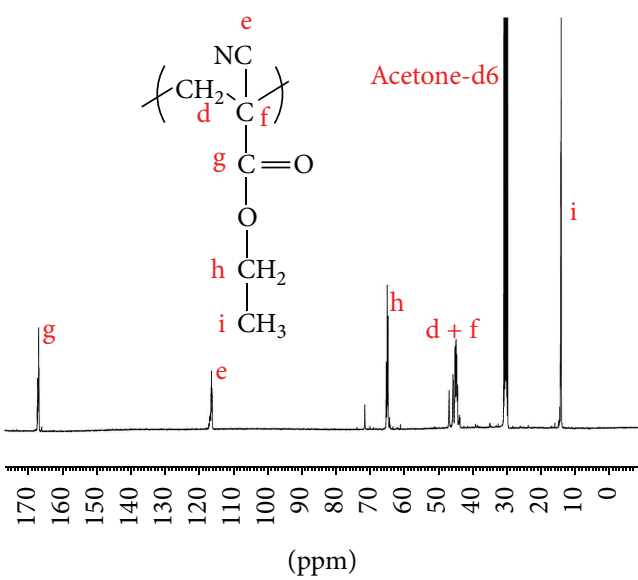

(b)

Figure 5: ${ }^{1} \mathrm{H}(\mathrm{a})$ and ${ }^{13} \mathrm{C}(\mathrm{b}) \mathrm{NMR}$ spectra of a sample of the polymer from the polymerization at a monomer dosing rate of $0.011 \mathrm{~g} / \mathrm{min}$.

addition rate and conversions larger than $40 \%$ reduces the number density of particles and consequently the ratio of reactive particles to protons, causing a drop in molecular weight.

As pointed out previously, in the polymerization of alkyl cyanoacrylates in aqueous dispersions stabilized with surfactants, it is usual to obtain polymers with low molecular weights. This could be due to a high termination rate of growing chains as a consequence of the large availability of $\mathrm{H}^{+}$when the reaction is done at low pHs. The work of Das et al. [7] favors this hypothesis; these authors polymerized isobutyl cyanoacrylate in aqueous dispersions stabilized with a surfactant and at pHs between 2 and 7; the obtained values of $M_{n}$ were between 1,000 and 13,000 $\mathrm{g} / \mathrm{mol}$ when the reactions were conducted at $\mathrm{pH}$ of 2 , but at $\mathrm{pH}$ of 7 , the obtained $M_{n}$ values were between 26,000 and $600,000 \mathrm{~g} / \mathrm{mol}$. Das et al. argued that, at low $\mathrm{pH}$ values, due to the high concentration of $\mathrm{H}^{+}$, the growing period of the chains is very short and as a consequence, oligomers or polymers of lower molecular weight are formed, whereas at higher pH's, the concentration of $\mathrm{H}^{+}$is lower, which leads to a longer polymer chain growing and larger molecular weights.

3.4. Chemical Structure Analysis. Figure 5 displays the ${ }^{1} \mathrm{H}$ and ${ }^{13} \mathrm{C}$ NMR spectra of the polymeric material obtained at the end of the original polymerization carried out at $0.011 \mathrm{~g} / \mathrm{min}$. The similarity of these spectra with that reported for PECA in literature is noteworthy [34]. The ${ }^{1} \mathrm{H}$ NMR spectrum shows the absence of the peaks of the olefinic protons at $\delta 6.5$ and $\delta 7.5 \mathrm{ppm}$ indicating that there is no unpolymerized monomer. The broad peaks at $\delta 2.6-3.0 \mathrm{ppm}$ (a) are ascribed to the methylene group in the backbone of the chain, while the peaks at $\delta 4.3$ (b) and $\delta 1.3 \mathrm{ppm}$ (c) are due to the protons of pending methylene and methyl groups, respectively. Meanwhile, the signals detected in the ${ }^{13} \mathrm{C}$ NMR spectra were $\delta 116(\mathrm{e})$, assigned to the carbon in the cyano group, the peaks at $\delta 43$ to $\delta 47 \mathrm{ppm}$, which corresponds to the carbon of methylene and quaternary carbon in the backbone chain $(\mathrm{d}+\mathrm{f})$, the peak at $\delta 167 \mathrm{ppm}(\mathrm{g})$, due to the carbon

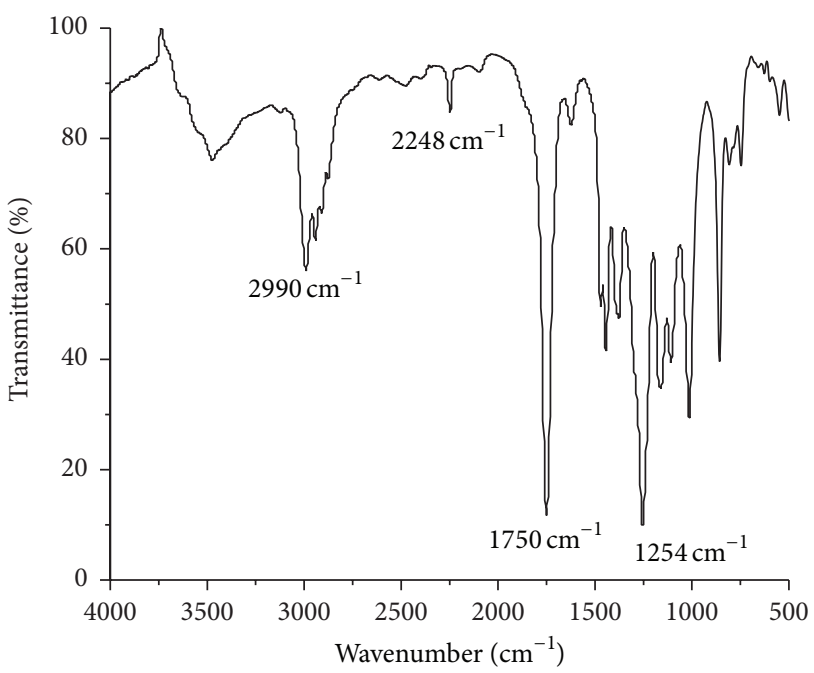

FIGURE 6: FTIR spectrum of a sample of the polymer from the polymerization at a monomer dosing rate of $0.011 \mathrm{~g} / \mathrm{min}$.

in the carboxyl group, and the peaks at $\delta 65 \mathrm{ppm}(\mathrm{h})$ and $\delta$ $14 \mathrm{ppm}(\mathrm{i})$, related to the carbons of the pendant methylene and methyl groups, respectively.

The FTIR spectra corresponding to the polymeric material collected at the end of the original polymerization carried out at $0.011 \mathrm{~g} / \mathrm{min}$ are shown in Figure 6. This spectra match well with those reported for PECA in the literature [34, 35]. In this spectra the peak at $2990 \mathrm{~cm}^{-1}$, which is ascribed to the symmetric and asymmetric $\mathrm{C}-\mathrm{H}$ stretching vibrations of methylene and methyl groups in the pendant ethyl, the peak at $2248 \mathrm{~cm}^{-1}$, due to the $\mathrm{C} \equiv \mathrm{N}$ stretching, at $1750 \mathrm{~cm}^{-1}$, a peak corresponding to the $\mathrm{C}=\mathrm{O}$ group stretching, and, finally, the peak at $1254 \mathrm{~cm}^{-1}$, attributed to the $\mathrm{C}-\mathrm{O}$ stretching, can be identified. The absence of absorbance at around $3130 \mathrm{~cm}^{-1}$, signal ascribed to $\mathrm{C}=\mathrm{CH} 2$ stretching in the monomer [35], is evident.

In this way, it can be concluded that the detected signals in the NMR and FTIR spectrum in Figures 5 and 6, respectively, 


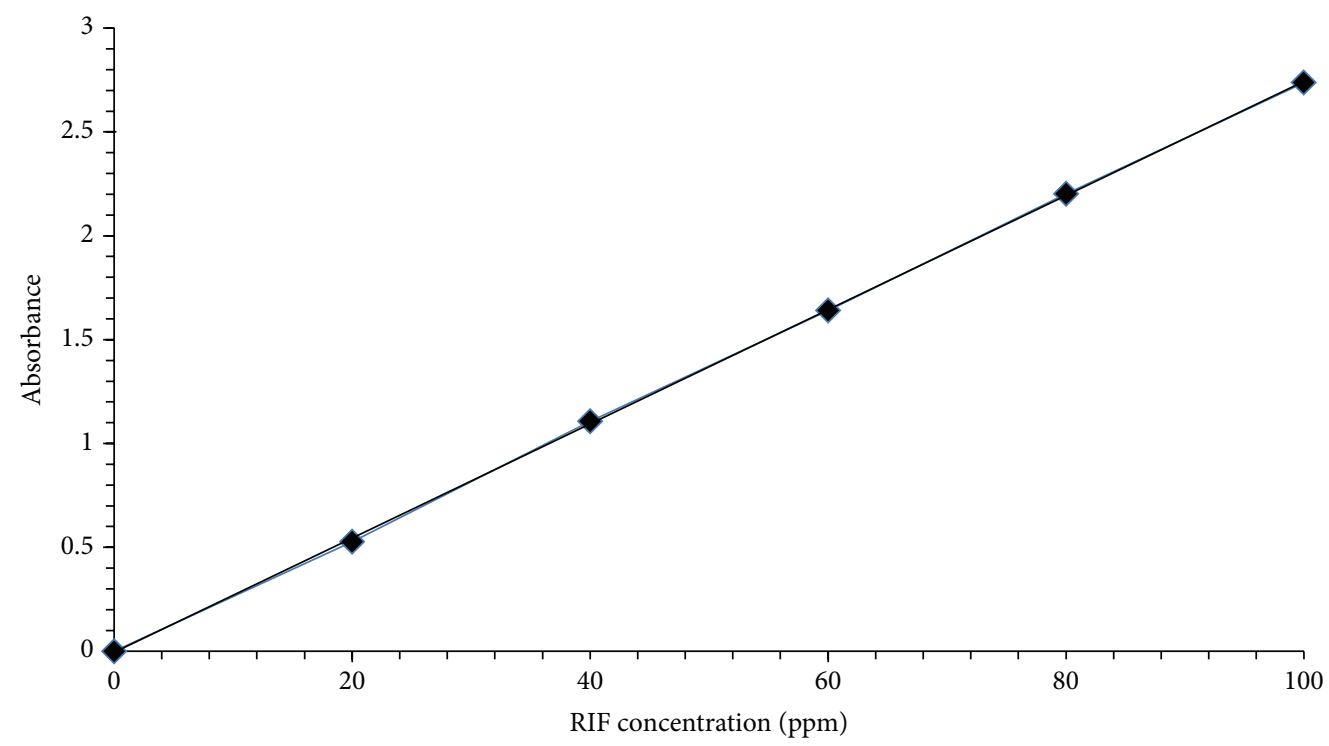

FIGURE 7: UV calibration curve for RIF dissolved in spectrophotometric grade chloroform at an absorbance of $348 \mathrm{~nm}$. Fit equation: $y=$ $0.0275 x-0.0055 ; R^{2}=0.9999$.

demonstrate that PECA was obtained in the polymerizations carried out in this study.

3.5. RIF Loading in Particles and Release Tests. For the drug loading of the particles, we used the latex obtained from the polymerization carried out at $0.011 \mathrm{~g} / \mathrm{min}$, which reached $97.6 \%$ conversion with $11 \%$ of total solids. According to the employed recipe, the expected content of RIF if the entire drug was loaded would be $12.6 \%$. For its part, the sample of RIF-loaded particles analyzed by UV-vis spectrophotometry gave a mean absorbance of 0.6817 at $348 \mathrm{~nm}$ in wavelength, which corresponds to $12.5 \%$ of drug in the particles, according to the calibration curve (Figure 7). This indicates that the entire drug charged was loaded in the PECA particles, within the experimental error.

RIF-loaded particles were not characterized by STEM, taken into account that there is no reason to change the particle size distribution as a result of the RIF loading. A simple calculation assuming additive volumes indicates that the increase in the particle diameter resulting from the incorporation of RIF to reach $12.5 \mathrm{wt} . \%$ in the particles is about only $4.6 \%$. This is equivalent to an increase of about $1.3 \mathrm{~nm}$ in $D_{n}$; moreover, there is no reason to expect a change in the PDI of PECA nanoparticles.

Figure 8 depicts the results of the drug release tests from the free RIF dispersed in $2 \mathrm{~mL}$ phosphate buffer solution in the bag dialysis and from the RIF-loaded particles. The release profiles are similar for both systems at short release times $(<4$ hours), but then they depart, the drug release being higher in the free RIF as expected since the drug into the nanoparticles has to diffuse through the polymer chains of the nanoparticles to reach the wall of the dialysis membrane. After 10 hours, the drug released from the bag containing free RIF is even larger than the one released from the nanoparticles; in fact, after 26 hours, most of the free RIF have been released,

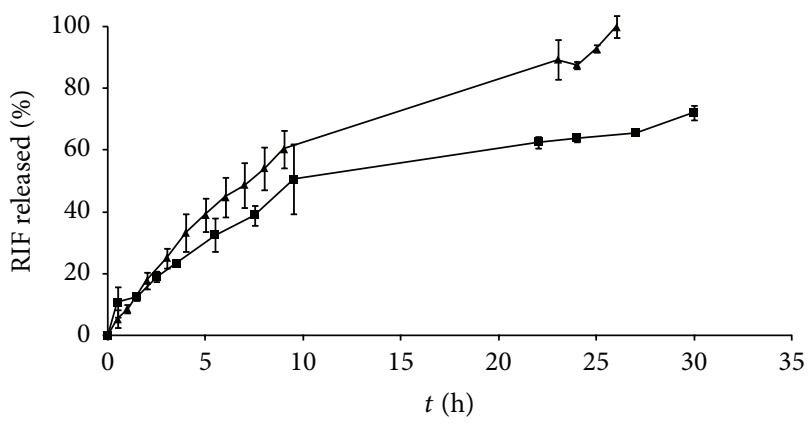

FIgURE 8: Drug release profiles from RIF-loaded PECA nanoparticles $(\boldsymbol{\square})$ and free $\operatorname{RIF}(\mathbf{\Delta})$.

whereas only $70 \%$ of the drug has been released from the nanoparticles after 30 hours. Elsewhere the relatively rapid drug release from nanoparticles compared to larger particles has been documented [36]. We propose here to explain this faster release that the distance that the drug must diffuse to reach the surface is shorter, especially for the molecules that are closer to the surface; moreover, this release time could be reduced if the drug forms a solid solution in the particles instead of aggregating to form crystals.

To determine the mechanism of drug release from the particles, several models were compared: in particular, those of order zero and order one, Higuchi and Korsmeyer-Peppas [37]. The drug release data was plotted in the linearized form of each of these models (Figure 9). According to the plots shown in this figure and taking into account the mean standard deviation of the data used to make the linearized form of these models, the Higuchi model gave the best fitting correlation of the data. The equation of the Higuchi model is the following [37]:

$$
C=K t^{1 / 2} .
$$




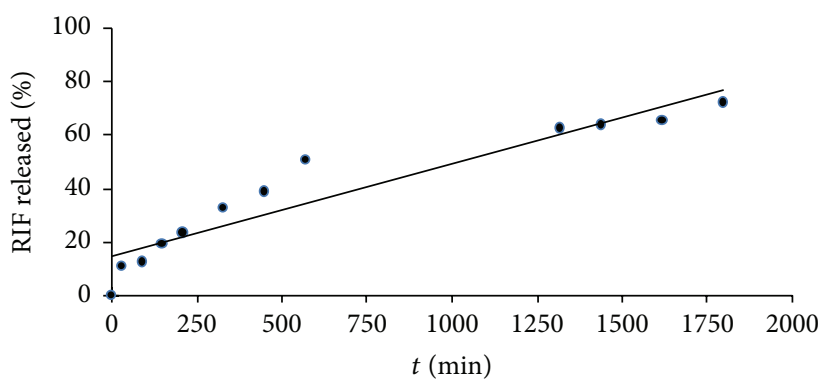

(a)

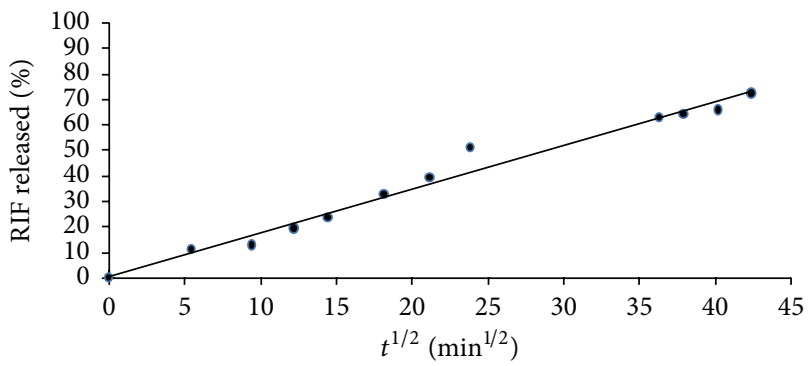

(c)

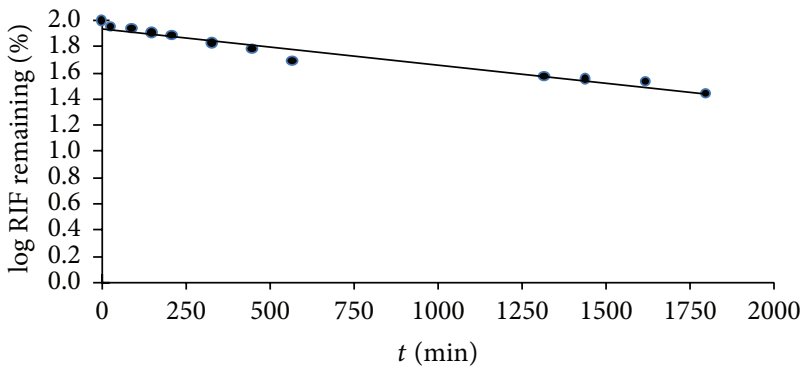

(b)

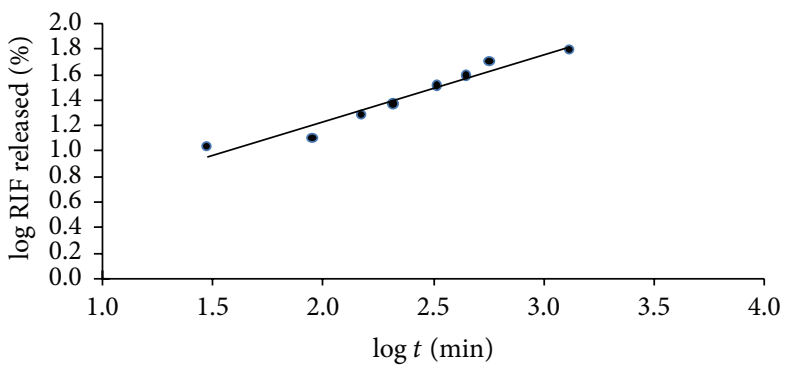

(d)

FiguRE 9: Release models tested for RIF released from PECA nanoparticles: zero order (a), first order (b), Higuchi (c), and Korsmeyer-Peppas (d). Fit equations: $y=0.034 x+14.53, R^{2}=0.896$ (a); $y=-0.000277 x+1.9425, R^{2}=0.959$ (b); $y=1.706 x-0.516, R^{2}=0.979$ (c); and $y=0.525 x+0.177, R^{2}=0.948(\mathrm{~d})$.

Here $C$ is the \% drug release, $K$ the kinetic constant, and $t$ the measured release time. Even though we expected that the best model to reproduce the drug release was that of Korsmeyer-Peppas because it considers both drug diffusion and particle erosion, the drug release follows a Fick diffusion mechanism, in accordance with Higuchi's model, due only to a concentration gradient within the system [38]. As is well known, the particle erosion comes from the hydrolysis of the pendant ester groups of PECA, which, given the obtained results, did not take place during the period of the release tests [39]. However, it is also known that PECA hydrolysis is promoted mainly by enzymes such as those in the blood plasma, which were absent in the release studies [39]. This fact could explain why the Fick diffusion model fits better the experimental data reported here.

\section{Conclusions}

A method to prepare PECA nanoparticles with mean diameter around $30 \mathrm{~nm}$ dispersed in a latex containing about $11 \%$ of total solids was disclosed. To our best knowledge there are no previous reports in the specialized literature showing the preparation of latexes containing so small PACA particles in conjunction with a solid content as high as the one obtained in this work. The study reveals that by decreasing the monomer addition rate, it is possible to obtain even smaller particles; however, at the slowest addition rate employed here, a fraction of them aggregate to finally give a bimodal population of sizes. The PECA nanoparticles were loaded with RIF obtaining a loading efficiency of $100 \%$ and $12.6 \%$ of drug content. The release tests showed that RIF diffuses slower from the nanoparticles in comparison with that from a dialysis bag containing the free drug, following a Fick diffusion mechanism in accordance with the Higuchi model.

\section{Competing Interests}

The authors do not report conflict of interests whatsoever.

\section{Acknowledgments}

National Council of Science and Technology (CONACyT) supported this research through Grants 2014-223227 and 232753 (Laboratorio Nacional de Materiales Grafénicos). C. Barrera acknowledges the scholarship from CONACyT. The authors are grateful to Juan U. Peña, José L. de la Peña, and Judith Cabello for their technical assistance.

\section{References}

[1] A. Graf, A. McDowell, and T. Rades, "Poly(alkycyanoacrylate) nanoparticles for enhanced delivery of therapeutics-is there real potential?" Expert Opinion on Drug Delivery, vol. 6, no. 4, pp. 371-387, 2009.

[2] G. Yordanov, "Poly (alkil cyanoacrylate) nanoparticles as drug carriers: 33 years later," Bulgarian Journal of Chemistry, vol. 1, no. 2, pp. 61-72, 2012.

[3] C. Vauthier, D. Labarre, and G. Ponchel, "Design aspects of poly(alkylcyanoacrylate) nanoparticles for drug delivery," Journal of Drug Targeting, vol. 15, no. 10, pp. 641-663, 2007.

[4] P. Couvreur, B. M. Kante, M. Roland, P. Guiot, P. Bauduin, and P. Speiser, "Polycyanoacrylate nanocapsules as potential lysosomotropic carriers: preparation, morphological and sorptive properties," Journal of Pharmacy and Pharmacology, vol. 31, no. 1, pp. 331-332, 1979. 
[5] S. J. Douglas, L. Illum, and S. S. Davis, "Particle size and size distribution of poly(butyl 2-cyanoacrylate) nanoparticles. II. Influence of stabilizers," Journal of Colloid and Interface Science, vol. 103, no. 1, pp. 154-163, 1985.

[6] B. Seijo, E. Fattal, L. Roblot-Treupel, and P. Couvreur, "Design of nanoparticles of less than $50 \mathrm{~nm}$ diameter: preparation, characterization and drug loading," International Journal of Pharmaceutics, vol. 62, no. 1, pp. 1-7, 1990.

[7] S. K. Das, I. G. Tucker, D. J. T. Hill, and N. Ganguly, "Evaluation of poly(isobutylcyanoacrylate) nanoparticles for mucoadhesive ocular drug delivery. I. Effect of formulation variables on physicochemical characteristics of nanoparticles," Pharmaceutical Research, vol. 12, no. 4, pp. 534-540, 1995.

[8] S. C. Yang, H. X. Ge, Y. Hu, X. Q. Jiang, and C. Z. Yang, "Formation of positively charged poly(butyl cyanoacrylate) nanoparticles stabilized with chitosan," Colloid and Polymer Science, vol. 278, no. 4, pp. 285-292, 2000.

[9] I. Bertholon-Rajot, D. Labarre, and C. Vauthier, "Influence of the initiator system, cerium-polysaccharide, on the surface properties of poly(isobutylcyanoacrylate) nanoparticles," Polymer, vol. 46, no. 4, pp. 1407-1415, 2005.

[10] C. K. Weiss, U. Ziener, and K. A. Landfester, "A route to nonfunctionalized and functionalized poly( $n$-butylcyanoacrylate) nanoparticles: preparation in miniemulsion," Macromolecules, vol. 40, no. 4, pp. 928-938, 2007.

[11] S. J. Douglas, L. Illum, S. S. Davis, and J. Krueter, "Particle size and size distribution of poly(butyl-2-cyanoacrylate) nanoparticles: I. Influence of physicochemical factors," Journal of Colloid and Interface Science, vol. 101, no. 1, pp. 149-158, 1984.

[12] N. Behan, C. Birkinshaw, and N. Clarke, "Poly $n$-butyl cyanoacrylate nanoparticles: a mechanistic study of polymerisation and particle formation," Biomaterials, vol. 22, no. 11, pp. 1335$1344,2001$.

[13] C. Chauvierre, D. Labarre, and P. Couvreur, "Radical emulsion polymerization of alkylcyanoacrylates initiated by the redox system dextran-cerium (IV) under acidic aqueous conditions," Macromolecules, vol. 36, no. 16, pp. 6018-6027, 2003.

[14] A. Bootz, T. Russ, F. Gores, M. Karas, and J. Kreuter, "Molecular weights of poly(butyl cyanoacrylate) nanoparticles determined by mass spectrometry and size exclusion chromatography," European Journal of Pharmaceutics and Biopharmaceutics, vol. 60, no. 3, pp. 391-399, 2005.

[15] J. Wu and J.-H. Duan, "Study of co-encapsulated doxorubicin and curcumin poly(butyl cyanoacrylate) nanoparticles and reversion of multidrug resistance in MCF-7/ADR cell line," Journal of Chemical and Pharmaceutical Research, vol. 5, no. 10, pp. 415-423, 2013.

[16] S. Snipstad, S. Westrøm, Y. Mørch, M. Afadzi, A. Åslund, and C. de Lange Davies, "Contact-mediated intracellular delivery of hydrophobic drugs from polymeric nanoparticles," Cancer Nanotechnology, vol. 5, no. 1, article 8, 2014.

[17] H. E. Shahmabadi, F. Movahedi, M. K. M. Esfahani et al., "Efficacy of Cisplatin-loaded polybutyl cyanoacrylate nanoparticles on the glioblastoma," Tumor Biology, vol. 35, no. 5, pp. 47994806, 2014.

[18] S. K. B. Doun, S. E. Alavi, S. K. B. Esfahani, H. E. Shahmabadi, F. Alavi, and S. Hamzei, "Efficacy of Cisplatin-loaded poly butyl cyanoacrylate nanoparticles on the ovarian cancer: an in vitro study," Tumor Biology, vol. 35, no. 8, pp. 7491-7497, 2014.

[19] X. Zhao, W. Li, Q. Luo, and X. Zhang, "Enhanced bioavailability of orally administered flurbiprofen by combined use of hydroxypropyl-cyclodextrin and poly(alkyl-cyanoacrylate) nanoparticles," European Journal of Drug Metabolism and Pharmacokinetics, vol. 39, no. 1, pp. 61-67, 2014.

[20] H. Saade, S. Torres, C. Barrera, J. Sánchez, Y. Garza, and R. G. López, "Effect of $\mathrm{pH}$ and monomer dosing rate in the anionic polymerization of ethyl cyanoacrylate in semicontinuous operation," International Journal of Polymer Science, vol. 2015, Article ID 827059, 9 pages, 2015.

[21] A. Des Rieux, V. Fievez, M. Garinot, Y.-J. Schneider, and V. Préat, "Nanoparticles as potential oral delivery systems of proteins and vaccines: a mechanistic approach," Journal of Controlled Release, vol. 116, no. 1, pp. 1-27, 2006.

[22] M. Elsabahy and K. L. Wooley, "Design of polymeric nanoparticles for biomedical delivery applications," Chemical Society Reviews, vol. 41, no. 7, pp. 2545-2561, 2012.

[23] D. Thassu, M. Deleers, and Y. Pathak, Nanoparticulate Drug Delivery System, Informa Healthcare, New York, NY, USA, 2007.

[24] L. L. I. J. Booysen, L. Kalombo, E. Brooks et al., "In vivo/in vitro pharmacokinetic and pharmacodynamic study of spray-dried poly-(DL-lactic-co-glycolic) acid nanoparticles encapsulating rifampicin and isoniazid," International Journal of Pharmaceutics, vol. 444, no. 1-2, pp. 10-17, 2013.

[25] https://www.sigmaaldrich.com/content/dam/sigma-aldrich/ docs/Sigma/Product_Information_Sheet/1/r3501pis.pdf.

[26] L. Balaita, V. Maier, L. Verestiuc, and M. Popa, "Polymer nanoparticles for release of rifampicin," Advanced Science, Engineering and Medicine, vol. 5, no. 2, pp. 96-104, 2013.

[27] M. Rajan and V. Raj, "Formation and characterization of chitosan-polylacticacid-polyethylene glycol-gelatin nanoparticles: a novel biosystem for controlled drug delivery," Carbohydrate Polymers, vol. 98, no. 1, pp. 951-958, 2013.

[28] D. Pooja, L. Tunki, H. Kulhari, B. B. Reddy, and R. Sistla, "Characterization, biorecognitive activity and stability of WGA grafted lipid nanostructures for the controlled delivery of Rifampicin," Chemistry and Physics of Lipids, vol. 193, pp. 11-17, 2015.

[29] R. Ledezma, M. E. Treviño, L. E. Elizalde et al., "Semicontinuous heterophase polymerization under monomer starved conditions to prepare nanoparticles with narrow size distribution," Journal of Polymer Science, Part A: Polymer Chemistry, vol. 45, no. 8, pp. 1463-1473, 2007.

[30] M. G. Pérez-Garca, M. Rabelero, S. M. Nuño-Donlucas et al., "Semicontinuous heterophase polymerization of n-butyl methacrylate: effect of monomer feeding rate," Journal of Macromolecular Science, Part A: Pure and Applied Chemistry, vol. 49, no. 7, pp. 539-546, 2012.

[31] M. G. Pérez-García, A. G. Alvarado, M. Rabelero et al., "Semicontinuous heterophase polymerization of methyl and hexyl methacrylates to produce latexes with high nanoparticles content," Journal of Macromolecular Science, Part A: Pure and Applied Chemistry, vol. 51, no. 2, pp. 144-155, 2014.

[32] J. J. Krackeler and H. Naidus, "Particle size and molecular weight distributions of various polystyrene emulsions," Journal of Polymer Science Part C, vol. 27, no. 1, pp. 207-235, 1969.

[33] M. A. El-Egakey, V. Bentele, and J. Kreuter, "Molecular weights of polycyanoacrylate nanoparticles," International Journal of Pharmaceutics, vol. 13, no. 3, pp. 349-352, 1983.

[34] M. G. Han, S. Kim, and S. X. Liu, "Synthesis and degradation behavior of poly(ethyl cyanoacrylate)," Polymer Degradation and Stability, vol. 93, no. 7, pp. 1243-1251, 2008. 
[35] G. Yordanov and Z. Bedzhova, "Poly(ethyl cyanoacrylate) colloidal particles tagged with Rhodamine 6G: preparation and physicochemical characterization," Central European Journal of Chemistry, vol. 9, no. 6, pp. 1062-1070, 2011.

[36] D. P. Otto and M. M. de Villiers, "Why is the nanoscale special (or not)? Fundamental properties and how it relates to the design of nano-enabled drug delivery systems," Nanotechnology Reviews, vol. 2, no. 2, pp. 171-199, 2013.

[37] M. H. Shoaib, J. Tazeen, H. A. Merchant, and R. I. Yousuf, "Evaluation of drug release kinetics from ibuprofen matrix tablets using HPMC," Pakistan Journal of Pharmaceutical Sciences, vol. 19, no. 2, pp. 119-124, 2006.

[38] C. Vauthier, C. Dubernet, E. Fattal, H. Pinto-Alphandary, and P. Couvreur, "Poly(alkylcyanoacrylates) as biodegradable materials for biomedical applications," Advanced Drug Delivery Reviews, vol. 55, no. 4, pp. 519-548, 2003.

[39] P. Couvreur and C. Vauthier, "Polyalkylcyanoacrylate nanoparticles as drug carrier: present state and perspectives," Journal of Controlled Release, vol. 17, no. 2, pp. 187-198, 1991. 

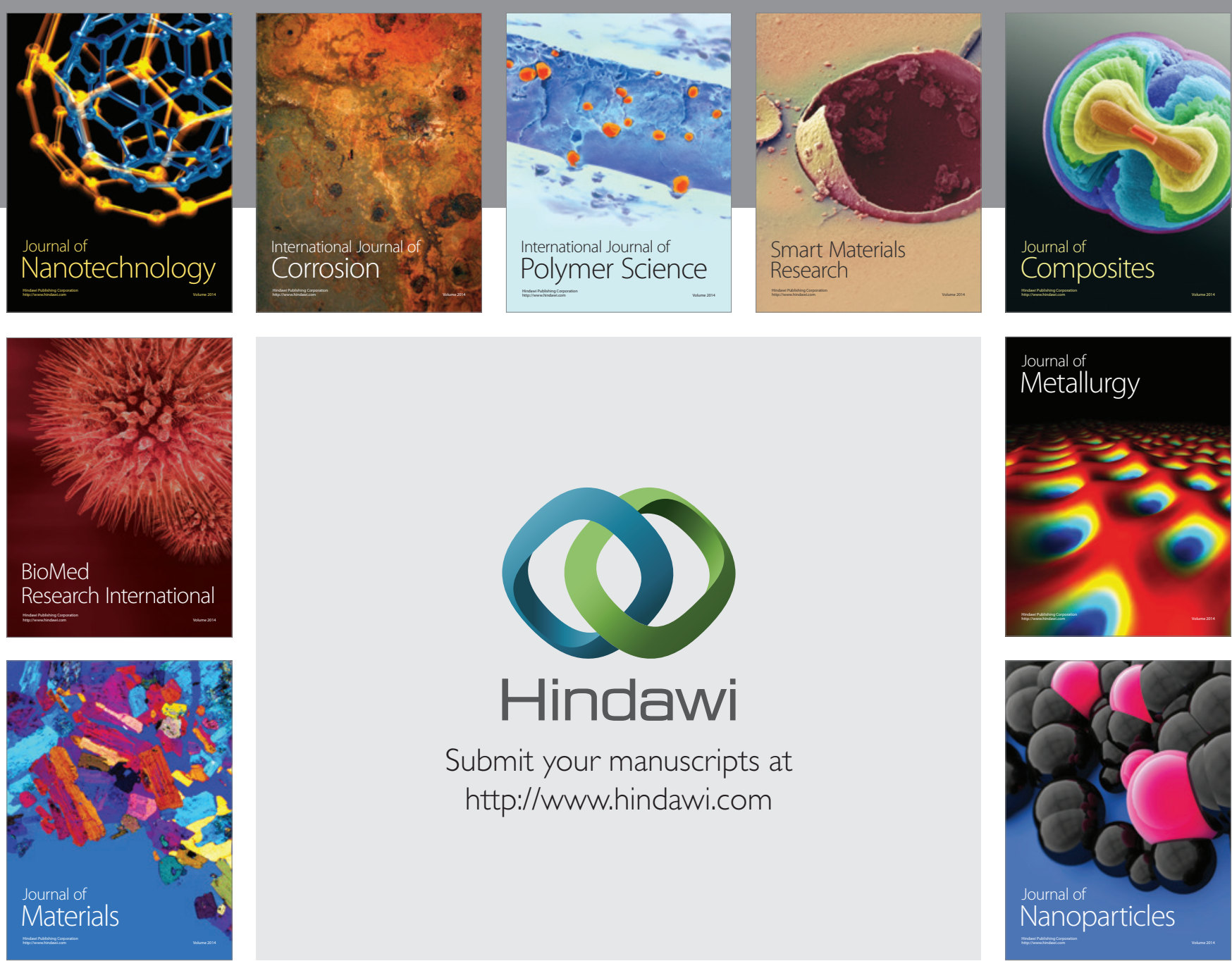

\section{Hindawi}

Submit your manuscripts at

http://www.hindawi.com

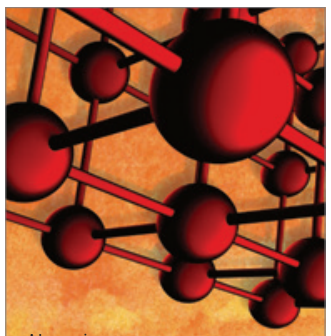

Materials Science and Engineering
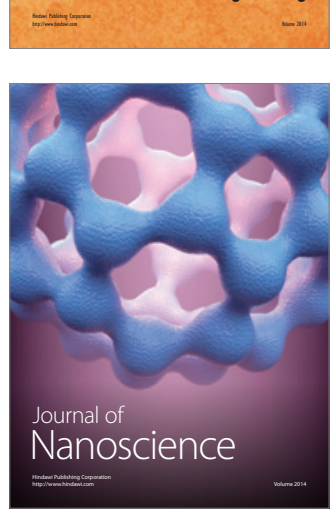
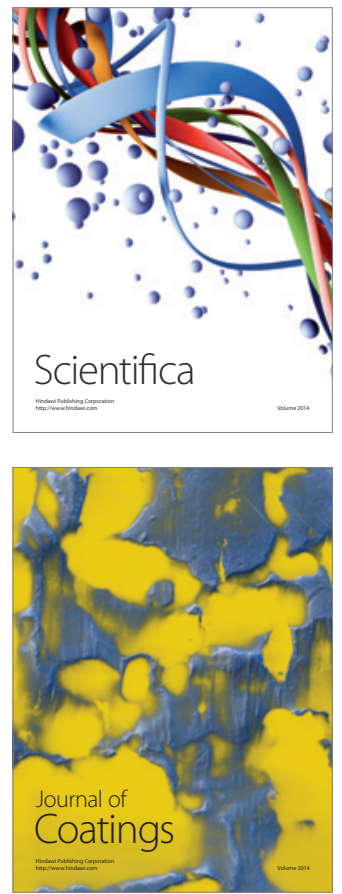
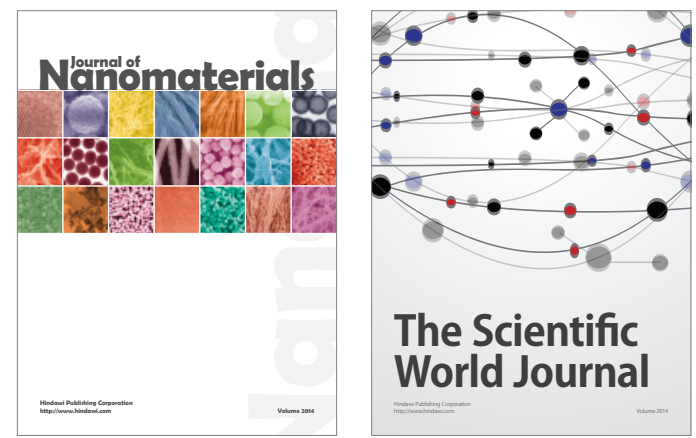

The Scientific World Journal
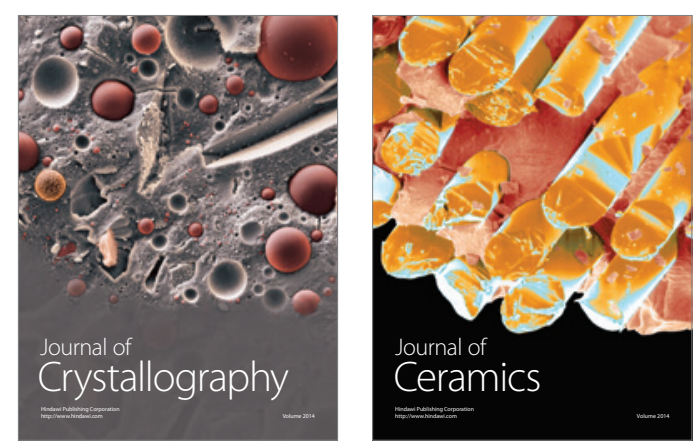
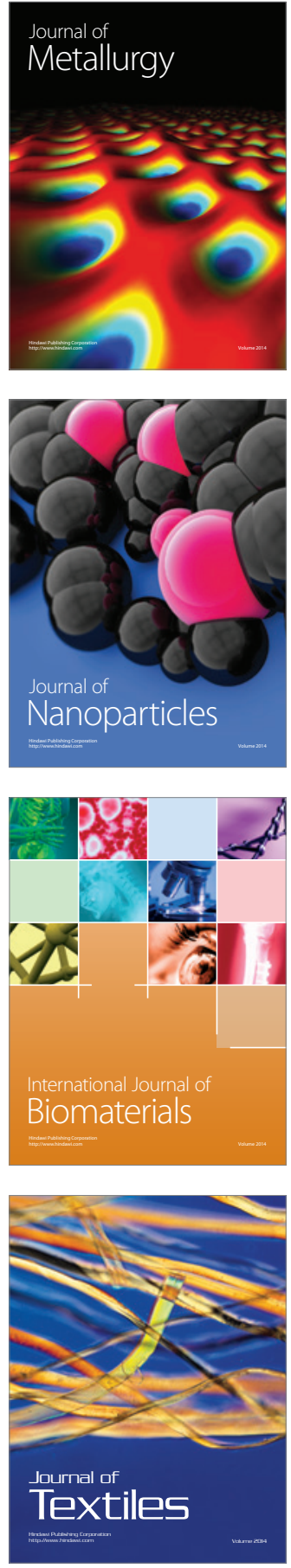